\title{
PHOTOVOLTAIC FED MULTILEVEL INVERTER DESIGN USING PODPWM TECHNIQUE FOR IMPROVED POWER QUALITY
}

\author{
Vijayalakshmi N, \\ Department of Electrical and Electronics Engineering, \\ Government Polytechnic College, \\ Madurai, India \\ vijayalashumi@gmail.com
}

\begin{abstract}
In this study, an efficient technique to improve and maintain the voltage levels of Cascaded H-Bridge Multi-Level Inverter (CHB-MLI) which utilizing PhotoVoltaic (PV) panel sources is presented. It is designed to make fifteen level output voltage and tested under the various levels of resistive loads. It produces staircase output with reduced component size, increases the output voltage level, reduces the voltage stress across the load/switches, reduces the Total Harmonic Distortion (THD) and increases the voltage gain. The switching pulses are generated using Phase Opposition Disposition (POD)Pulse Width Modulation (PWM) technique. It is modeled and simulated using SIMULINK graphical programming environment in MATLAB. Results prove that the system provides lower THD than conventional systems.
\end{abstract}

Keywords: Multi level inverter, CHB-MLI, POD-PWM, THD reduction, power quality

\section{INTRODUCTION}

The use of PV based energy sources are more popular nowadays and are used in generation and distribution frameworks and electric vehicles etc. The DCAC power converters including the voltage and current source inverter are used to acquire a suitable output from PV energy resources for such applications. PV systems are becoming much familiar than other renewable energy resources due to their advantages such as less maintenance, pollution-free and no fuel cost.

PV generation system requires advanced electronic devices for better power quality, to increase the generation and for proper utilization of generated energy [1-3]. As a result, researchers introduced many converters, inverters, and controllers. Multilevel inverters are more attention due to its attractive features such as maximum power, small voltage stress on the switch, and high output voltage gain with small harmonics [4-5].

Multilevel inverters are used in different areas like power system application such as static compensators [6-7], electric drives, industrial applications, and flexible alternative current transmission systems [8]. The available three superior types of multilevel inverters are diode clamped, flying capacitor, and CHI-MLI. H-bridge inverters are mainly considered because of fewer components and favorable conditions like isolation and electromagnetic similarity over different structures [9].

The main use of MLI is to reduce THD in the output voltage. THD can be reduced by using proper PWM techniques [10]. The different PWM methods available are phase shifted and level shifted PWM. The former one can be classified into phase disposition, POD, alternate POD, variable frequency, and 
finally carrier overlapping PWM. In [11-13], multi-carrier phase shifted PWM technique is used for cascaded seven-level inverter.

In this study, PV fed 15-level multilevel inverter using POD-PWM technique is presented for reducing the harmonic distortion and improving voltage level without transformer. Section 2 discusses the methods and materials used for the design of CHB-MLI using POD-PWM techniques. The next section provides the results obtained by the CHI-MLI system and the last section concludes the CHB-MLI system.

\section{METHODS AND MATERIALS}

Figure 1 shows the PV fed multilevel inverter design using POD-PWM technique for improved power quality. It consists of a PV source and CHB-MLI driven by POD-PWM technique. The voltage $\left(\mathrm{V}_{p v}\right)$ attained from the PV is feed to the CHB-MLI, which is connecting to the resistive load $\left(\mathrm{R}_{\text {load }}\right)$. Pulse is generated according to POD-PWM technique and given to the inverter for obtaining the desired fifteen level output voltage.

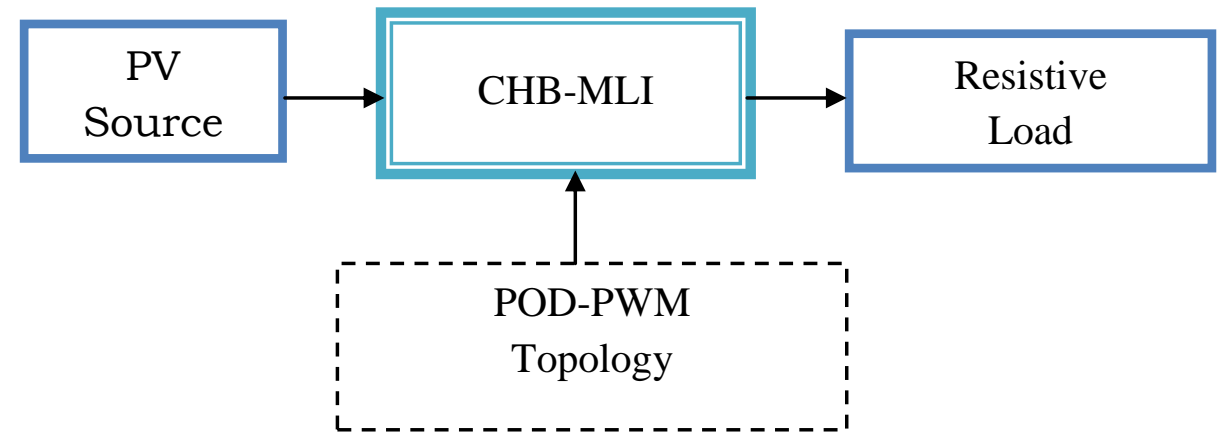

Fig. 1 Block diagram of PV fed multilevel inverter design

\section{A. Solar Panel}

In order to generate enough power to $\mathrm{R}_{\text {load, }}$ more $\mathrm{PV}$ panels can be combined as they require less maintenance. In simulation, PV is represented using 2-diode model as shown in Fig. 2. This model is highly efficient to provide better power to the load than the single diode model. The output current of the PV array can be represented as,

$$
I_{0}=I_{p h}-I_{D 1}-I_{D 2}-I_{R p}
$$




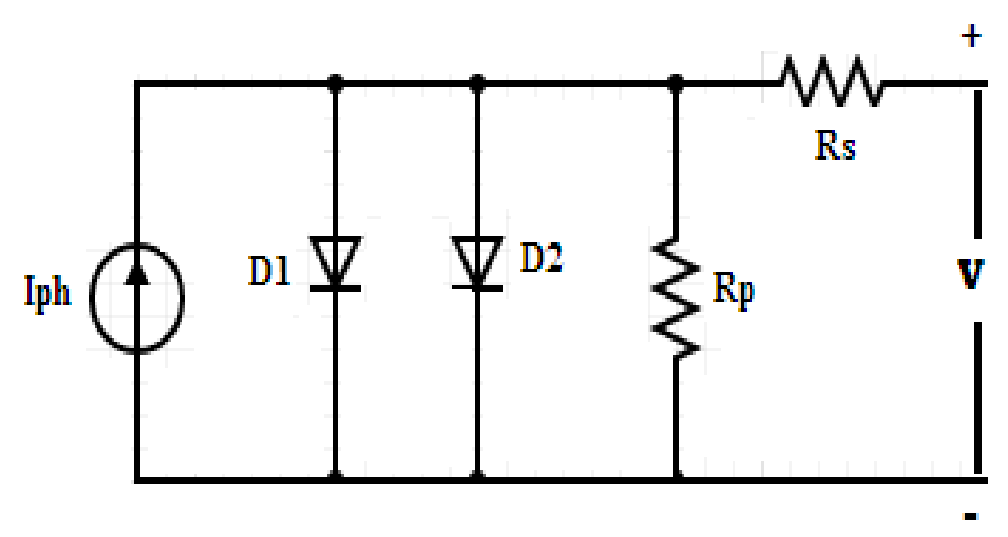

Fig. 2 Two diode model of PV

\section{B. CHB-MLI system}

The basic 5-level CHB-MLI formed with 8 switches is shown in Fig. 3. The sum of the output voltage of each H-bridge is the output of CHB-MLI. Any increase in the number of bridge will increase the output voltage level and it becomes similar to a sinusoidal waveform.

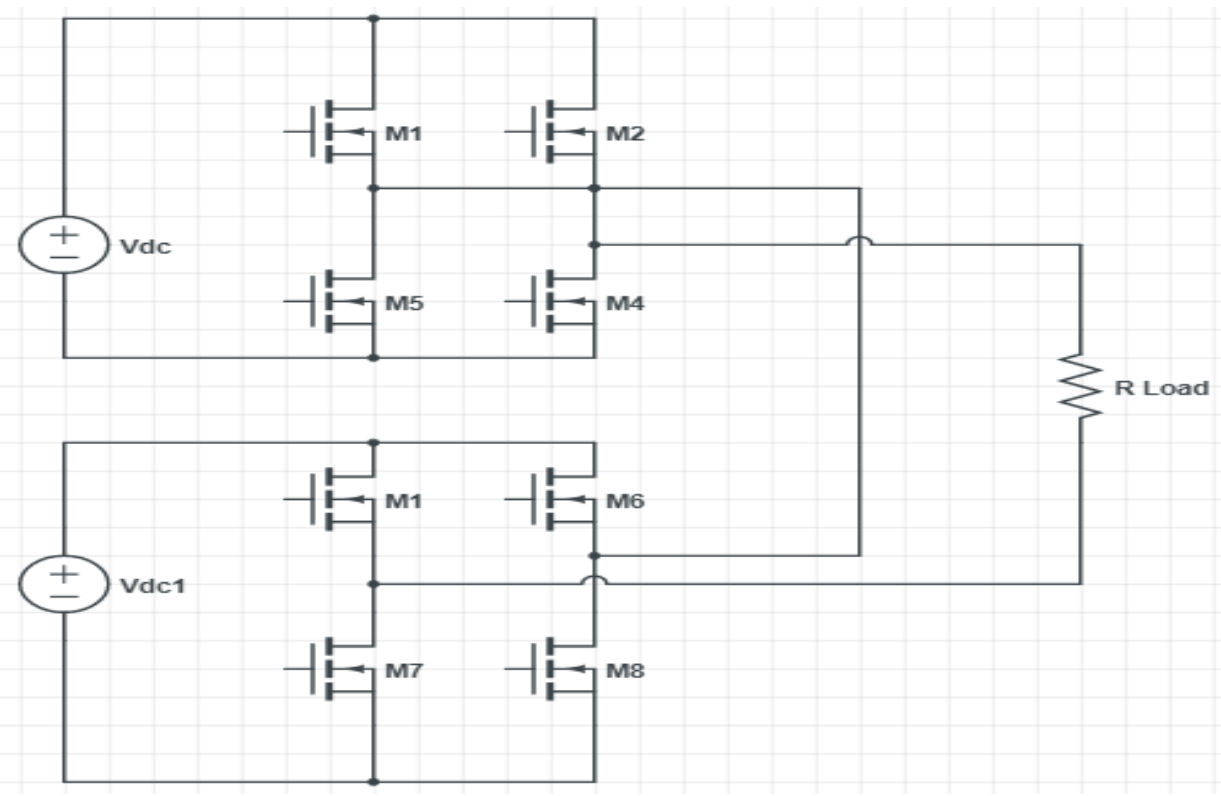

Fig. 3 Basic circuit diagram of CHB-MLI

\section{POD-PWM Technique}

It is one of the level shifted PWM techniques. PWM is generated, if the sine wave is greater or lesser than the carrier signals. Figure 4 shows the generalized diagram of POD-PWM. The carrier signals above and below zero are 180 degrees out of phase to each other. 


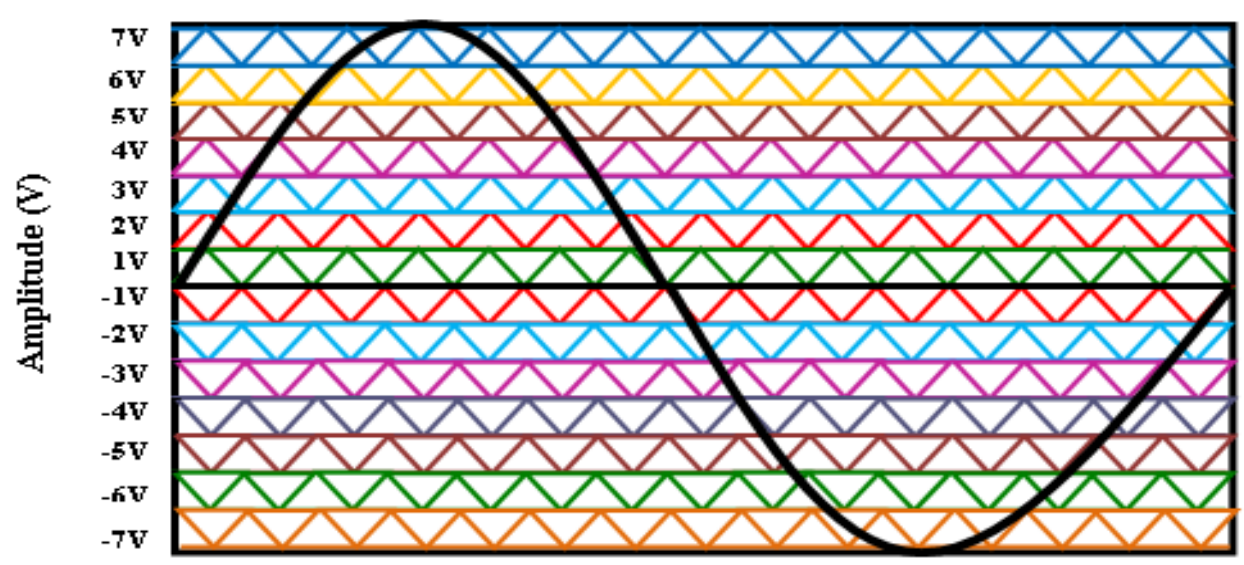

Time (S)

Fig. 4 Generalized representation of POD-PWM

\section{RESULTS AND DISCUSSION}

Figure 5 shows the MATLAB simulation diagram of the PV fed 15 levels CHB-MLI and the various configurations used in the simulation are listed in Table 1. The CHB-MLI is designed using 10 power semiconductor switches with three DC sources such as $12 \mathrm{~V}, 24 \mathrm{~V}$ and $48 \mathrm{~V}$. All switches are controlled by PWM pulses which are generated using POD-PWM method.

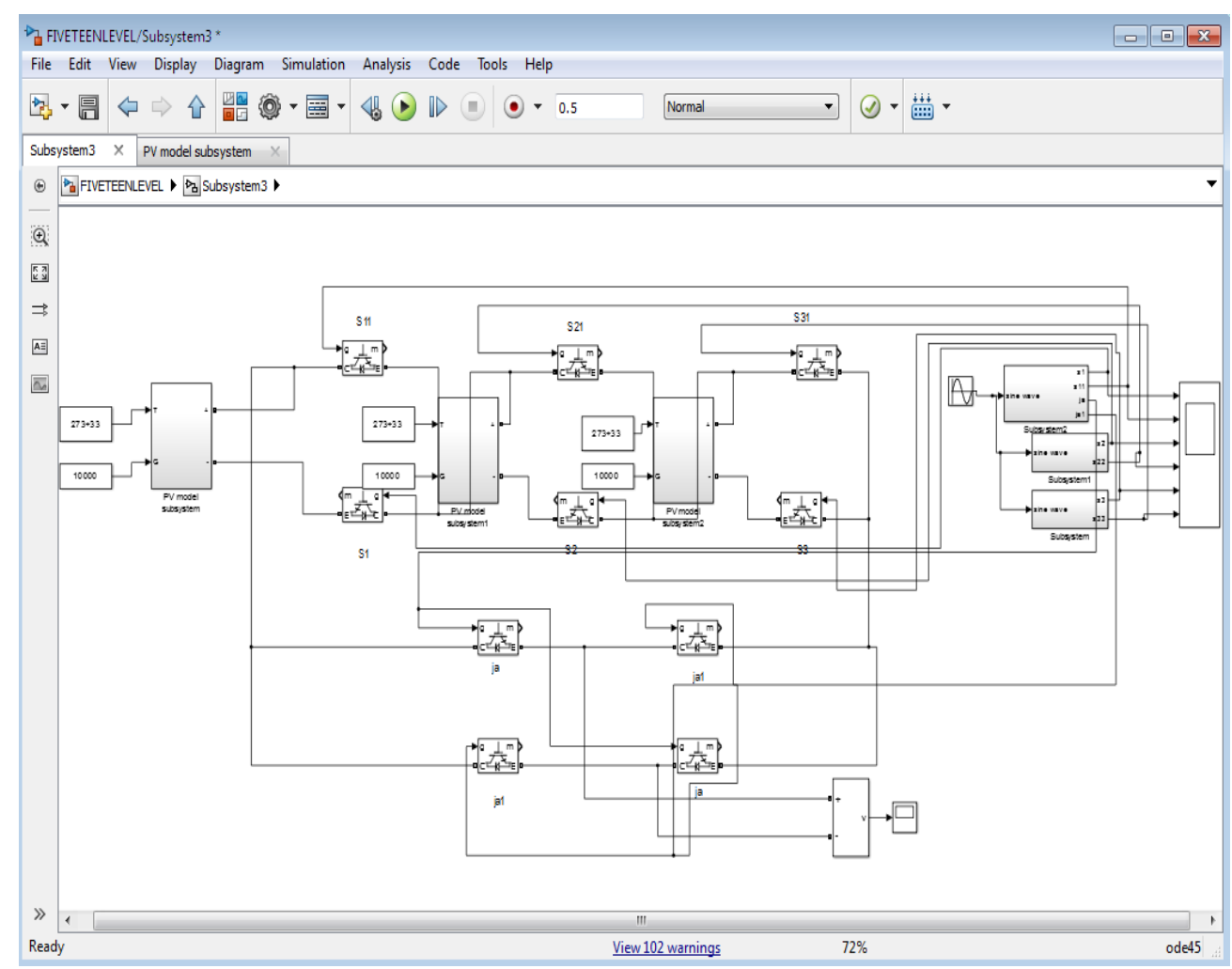

Fig. 5 Simulink diagram of 15-level CHB-MLI 


\section{TABLE 1 Simulation parameters}

\begin{tabular}{|c|c|}
\hline Parameter & Values \\
\hline $\begin{array}{c}\text { Three Separate Sources - } \\
\text { Solar Voltage }(\mathrm{V})\end{array}$ & $12 \mathrm{~V}, 24 \mathrm{~V}, 48 \mathrm{~V}$ \\
\hline Switching Frequency $(\mathrm{Fs})$ & $1500 \mathrm{~Hz}$ \\
\hline Carrier Frequency $(\mathrm{Fc})$ & $100 \mathrm{~Hz}$ \\
\hline
\end{tabular}

The POD-PWM pulses are generated by comparing a reference sine wave with triangular career waves. When the reference signal cuts the carrier signal it creates pulse to the semiconductor switches. The generation of POD-PWM is shown in Fig. 6. The 15-level output voltage waveform is shown in Fig. 7.

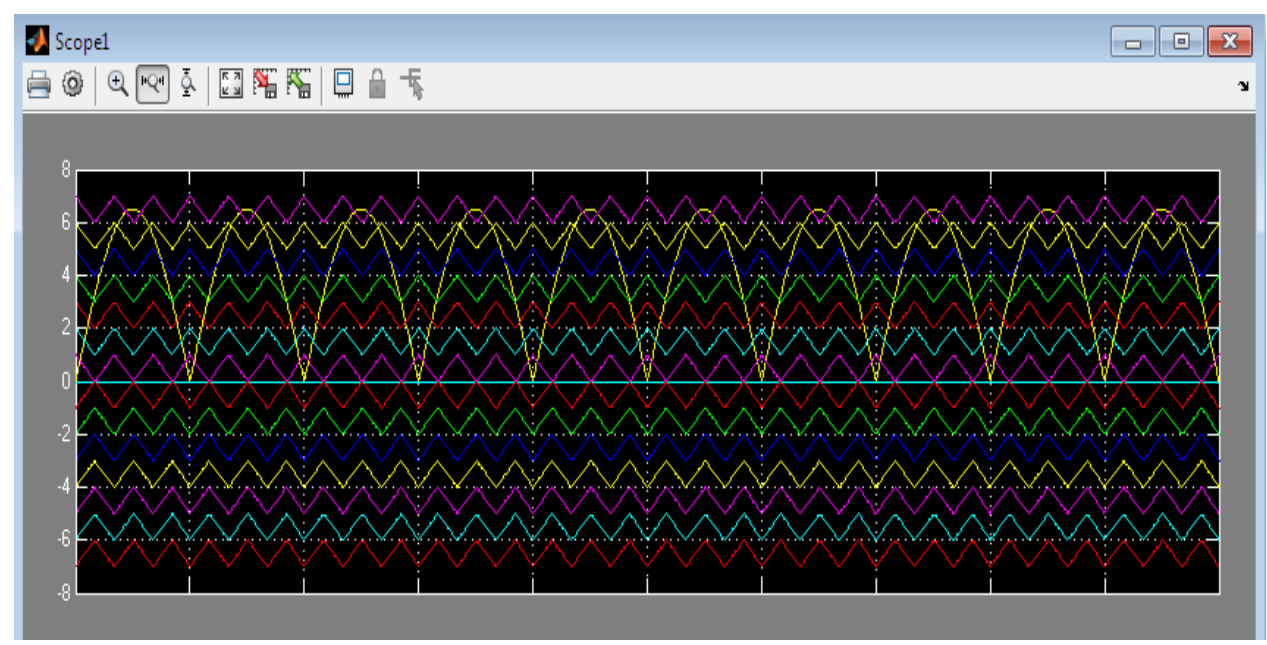

Fig. 6 Generation of POD-PWM

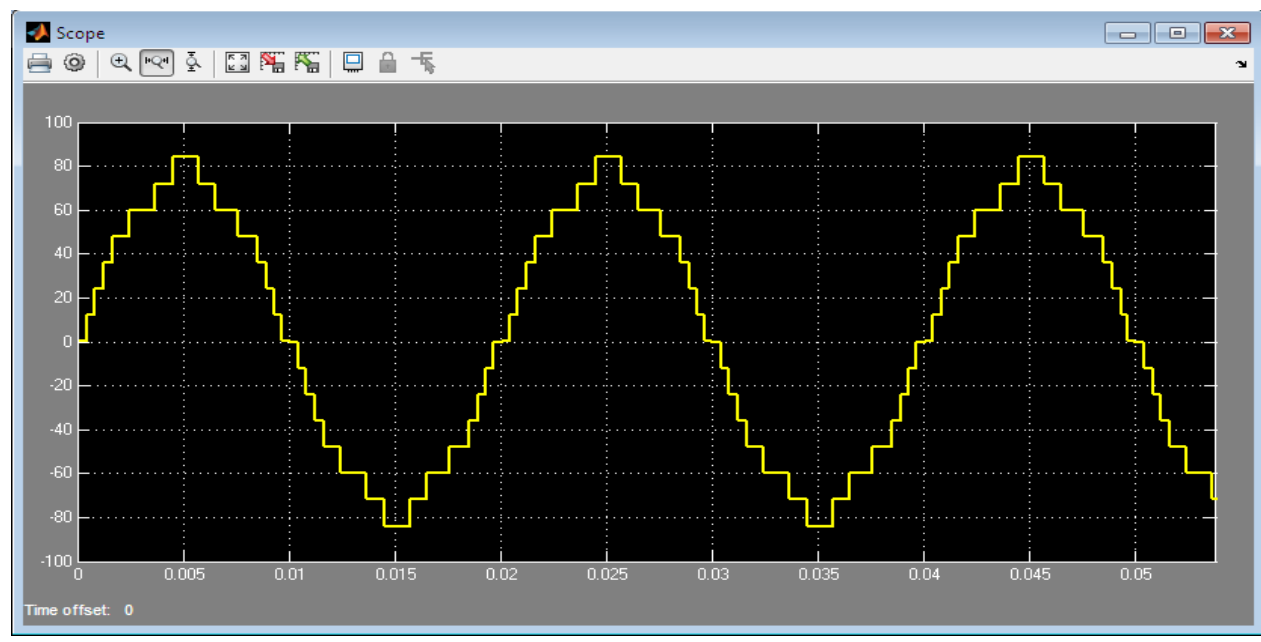

Fig. 7 Output voltage waveform of 15-level CHB-MLI 


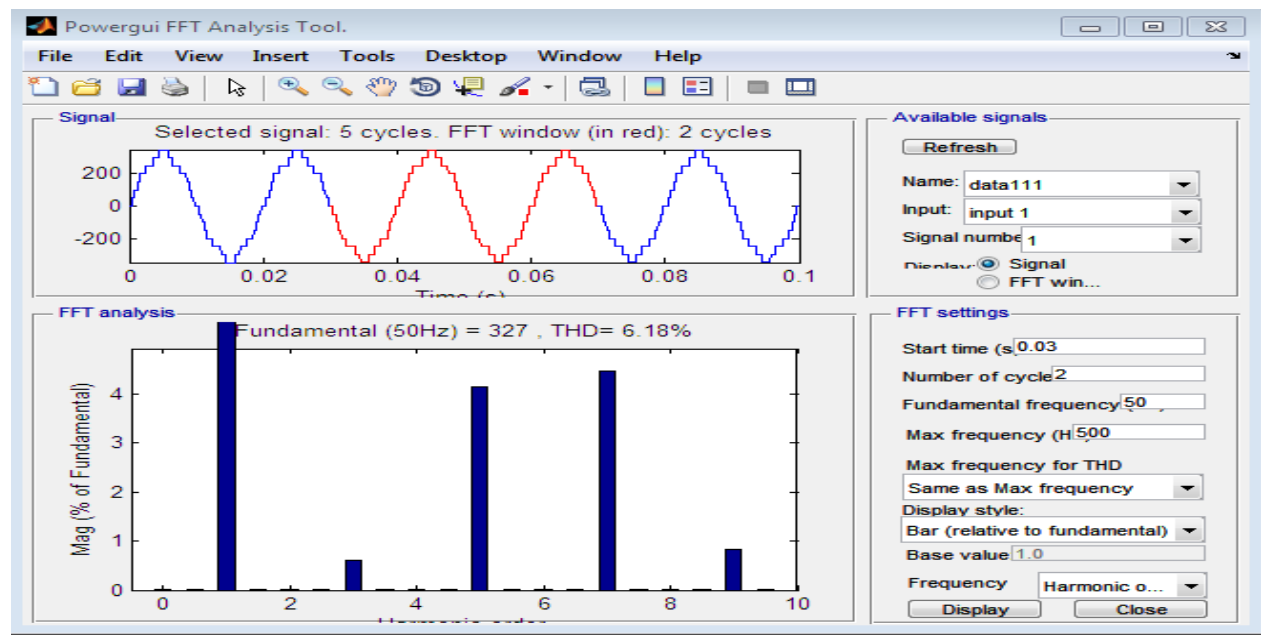

Fig. 8 THD in percentage

TABLE 2 Performance of 15-level CHB-MLI with conventional system

\begin{tabular}{|c|c|c|}
\hline Parameter & Conventional Method & Proposed Method \\
\hline Semiconductor switch & 12 & 10 \\
\hline Output voltage levels & 9 & 15 \\
\hline \%THD & 18.14 & 6.18 \\
\hline
\end{tabular}

From Table 2, it is inferred that conventional method consists of 12 switches and gives 9 level output with $18.14 \%$ of THD using POD-PWM whereas the CHB-MLI system consists of 10 switches and gives 15 level output voltage with $6.18 \%$ of THD using POD-PWM technique.

\section{CONCLUSION}

In this study, a design of PV fed 15-level CHB-MLI is presented. It is designed with 10 switches which are driven by POD-PWM technique and tested under the various levels of resistive loads. All the simulations are carried out in MATLAB simulink tool. The system achieves lesser THD of $6.18 \%$ whereas the conventional system has $18.14 \%$. Also, the output voltage of the inverter is 96 volts to -96 volts with the difference of $12 \mathrm{~V}$ between each level for input of 48 volts. Results show that the POD-PWM technique improves the voltage gain without the use of transformer and reduces the THD and it is concluded that POD-PWM is best suitable for MLI.

\section{REFERENCES}

[1]. B.M. Kiran, B.S. Ram, "Fault detection and mitigation in cascaded MLI fed EV", International Conference on Advances in Electrical, Electronics, Information, Communication and Bio-Informatics, 2016, pp. 491-498. 
[2]. B. Dinesh, M. Jaivinayagam, M. Udayakumar, and S. Syedismail, "solar photovoltaic array fed water pump riven by brushless dc motor using ky converter", International Journal of MC Square Scientific Research, Vol. 9, No. 1, 2017, pp. 183-188.

[3]. P.A. Salodkar, P.S. Kulkarni, and M.A. Waghmare, "Study of single-phase multilevel inverter topologies suitable for photovoltaic applications", International Conference on Energy, Communication, Data Analytics and Soft Computing, 2017, pp. 2315-2318.

[4]. C.K. Kishore, K. Balaji, J. Madhavan, "Modified Cascaded Switched Diode Multilevel inverter with multiple outputs and reduced harmonic content", International Conference on Innovations in Information and Communication Technology, 2019, pp. 1-4.

[5]. V. Vasudevan, K. Balaji, "Modeling and Dynamic Performance of Photovoltaic and Fuel Cell Power Generation for Hybrid Converter System", Medico-Legal Update, Vol. 18, No. 1, 2018, pp. 539-547.

[6]. S.P. Thiruvadi, S. Bhuvaneshwari, "Hybrid PV-Wind-Battery Based System for Household Applications Using DC-DC Converter", International Journal of MC Square Scientific Research, Vol. 9, No. 1, 2017, pp. 54-65.

[7]. R. Rajeswari, "Dynamic model and hybrid design of current fed switched inverter for DMPPT fuel cell systems", International journal of advances in signal and image sciences, Vol. 1, No. 1, 2015, pp. 29-40.

[8]. A. Sireesha, K.P. Swaroop, and G. Durga Prasad, "Generalized cascaded Multi Level Inverter using reduced number of components with PV systems", Biennial International Conference on Power and Energy Systems: Towards Sustainable Energy, 2016, pp. 1-7.

[9]. D. Sankar, and C.A. Babu, "Cascaded H bridge multilevel inverter topologies for PV application: A comparison", International Conference on Circuit, Power and Computing Technologies, 2016, pp. 1-5.

[10]. L. Xiong, Y. Gui, H. Liu, W. Yang, and J. Gong, "A hybrid CHB multilevel inverter with super capacitor energy storage for grid-connected photovoltaic systems", Applied Power Electronics Conference and Exposition, 2018, pp. 3195-3199.

[11]. S.R. Nandhini, G. Akalya, K. Aswini, K. Nandhini, "A New Topology of Hbridge based Multilevel Inverter for PV System with Reduced Switches", International Journal of Emerging Technologies in Engineering Research, Vol. 5, No. 4, 2017, pp. 60-68.

[12]. G. Schettino, S. Benanti, C. Buccella, M. Caruso, V. Castiglia, C. Cecati, A.O. Di Tommaso, R. Miceli, P. Romano, and F. Viola, "Simulation and experimental validation of multicarrier PWM techniques for three-phase five-level cascaded H-bridge with FPGA controller", International Journal of Renewable Energy Research, Vol. 7, No. 3, 2017, pp. 1383-1394.

[13]. F. Wang, Z. Li, H.T. Do, and D. Zhang, "A Modified Phase Disposition Pulse Width Modulation to Suppress the Leakage Current for the Transformer less Cascaded H-Bridge Inverters", IEEE Transactions on Industrial Electronics, Vol. 65, No. 2, 2018, pp. 1281-1289. 